\title{
Analisis Kelayakan Finansial Pada Tanaman Lada di Kabupaten Lampung Timur
}

\section{The Analysis of Financial Expendiency on Pepper Plant in East Lampung Regency}

\author{
Zulkarnain $^{1^{*}}$, dan Muhamad Gary Ranchiano ${ }^{2}$ \\ ${ }^{1,2}$ Sekolah Tinggi Ilmu Pertanian Dharma Wacana \\ * E-mail : zulfadhilalzabir@gmail.com
}

\begin{abstract}
The role of the agricultural sector in Indonesia is led to increasing agricultural production. One of the sub-sectors in the agricultural sector that give quite a big contribution to the national economy is the farming plant sub-sector. One of the export commodities from the farming plant sub-sector that has an important role in the economy is the pepper plant. Farming plant productivity had not been optimum and farmers paid low attention to the quality of their plants so that it will affect the price in which it will also give the influence to profit level of them that will get smaller, while, life necessity is getting bigger. The study aimed to analyze the financial expediency of pepper plants in the district of Margatiga, East Lampung regency. The location of the study was in Margatiga district, East Lampung regency. The respondents in this study were pepper farmers in Margatiga districts, East Lampung regency with the total was 56 farmers who had been chosen by simple random sampling. Financial analysis was used to answer the research question. The finding result shows that pepper farmings in the district of Margatiga in East Lampung regency were financially profitable and feasible to develop.
\end{abstract}

Keywords: Expediency, Financial, Pepper

Disubmit: 13 Mei 2019; Diterima: 20 Juni 2019; Disetujui: 20 November 2019

\section{PENDAHULUAN}

Pembangunan ekonomi berbasis pertanian secara langsung maupun tidak langsung akan berdampak pada perekonomian nasional yang dapat mengurangi penduduk miskin (Mangiring, 2017). Oleh karena itu, peranan sektor pertanian di Indonesia diarahkan untuk meningkatkan produksi pertanian yang bertujuan untuk memenuhi kebutuhan pangan masyarakat, bahan baku industri dalam negeri, meningkatkan kemampuan ekspor, meningkatkan pendapatan petani, dan mendorong kesempatan berusaha. Salah satu subsektor di sektor pertanian yang memberikan kontribusi yang cukup besar bagi perekonomian nasional adalah subsektor tanaman perkebunan. Subsektor tanaman perkebunan menjadi makin penting dikarenakan makin terbatasnya peranan migas dan kehutanan yang beberapa dekade lalu merupakan sumber devisa utama bagi Indonesia (Suwanto, 2017). Kontribusi subsektor tanaman perkebunan dapat dilihat dari nilai ekspor komoditas pertanian selama tahun 2017 sebesar USD 2,61 milyar sebagian besar di sumbang dari subsektor tanaman perkebunan yakni sebesar USD 2,52 atau 96,43 \% (Kementerian Pertanian, 2018) 
Salah satu komoditas ekspor dari subsektor tanaman perkebunan yang mempunyai peranan penting dalam perekonomian sebagai sumber devisa maupun sumber mata pencaharian petani adalah lada (Sumantri, Priyono, \& Isronita, 2004). Lada adalah "King of Spice" atau raja tanaman rempah yang kini menjadi komoditas penting perdagangan dunia. Tanaman lada memiliki peran penting dalam penghasil devisa, penyedia lapangan kerja, sebagai bahan konsumsi dan bahan baku industri (Fatimah, 2013). Untuk mengembangkan subsektor tanaman perkebunan maka perkebunan rakyat harus mendapat perhatian yang cukup serius, karena perkebunan rakyat memiliki kondisi karakteristik dengan tingkat produktivitas yang masih rendah, skala usahataninya kecil dan tidak memiliki akses pasar serta kondisi sosial ekonomi yang lemah. Perkebunan rakyat memilki banyak masalah dan kendala yang berdampak pada produktivitas yang masih sangat rendah. Produktivitas yang rendah tersebut berpengaruh terhadap pendapatan petani (Syamsuddin \& Hatta Muhammad, 2014). Sedangkan perkebunan besar memiliki kemampuan teknologi, manajemen dan pasca panen yang sudah baik.

Pada tahun 2014, produksi lada hitam dunia mencapai 337.200 ton dan Vietnam merupakan negara penghasil dan pengekspor terbesar lada hitam dengan produksi mencapai 125.000 ton atau sekitar $37 \%$ dari total produksi dunia, kemudian diikuti Indonesia 52.000 ton $(15,4 \%)$, India 37.000 ton (11\%), Brasil 36.000 ton $(10,7 \%)$ dan China 27.500 ton $(8,15 \%)$. (International Pepper Community (IPC), 2014). Produksi lada Indonesia sebagian besar diperuntukkan untuk ekspor. Dalam perdagangan internasional, volume ekspor lada Indonesia cenderung menurun karena kalah bersaing dengan lada dari Vietnam. Sebaliknya, volume impor lada, meskipun jauh lebih kecil daripada volume ekspor, tetapi meningkat pesat. Neraca perdagangan lada Indonesia hingga tahun 2014 masih berada pada posisi surplus (Suwanto, 2017)

Di Indonesia, tanaman lada sudah dibudidayakan sejak ratusan tahun yang lalu. Daerah sentral produsen utama lada di Indonesia adalah Propinsi Lampung untuk lada hitam dan Propinsi Bangka Belitung untuk lada putih. Kontribusi produksi lada dari Propinsi Lampung dan Propinsi Bangka Belitung sebesar 70$80 \%$ dari total produksi lada di Indonesia sedangkan sisanya sebesar 20-30\% berasal dari Kalimantan Barat, Kalimantan Timur, Sulawesi Selatan dan Jawa Barat. Berdasarkan data pada tahun 2010 produksi lada mencapai 83.663 Ton dan pada tahun 2014 meningkat menjadi 91.940 Ton (Kementerian Pertanian, 2015). Menurut data BPS Propinsi Lampung tahun 2015, di Propinsi Lampung komoditas lada merupakan komoditas ekspor utama setelah kopi. Pada tahun 2010 ekspor lada hitam mencapai 81.617 ton namun tahun-tahun berikutnya jumlahnya cenderung menurun dan pada tahun 2014 jumlah ekspor sebesar 15.226 ton (Dinas Perindustrian Propinsi Lampung, 2014). Salah satu kabupaten yang memberikan kontribusi produksi tanaman lada di Propinsi Lampung adalah Kabupaten Lampung Timur. Tanaman lada telah menjadi lokasi cagar budidaya lada hitam di Kabupaten Lampung Timur.

Tanaman lada masuk ke dalam 5 besar komoditas perkebunan yang diusahakan oleh petani di Kabupaten Lampung Timur, selain Kelapa, Kakao, Karet dan Kelapa sawit. Pada tahun 2014, Kabupaten Lampung Timur mempunyai luas areal tanaman lada sebesar 5.104 hektar dengan hasil produksi 2.023 ton dengan produktivitas rata-rata hanya 610 kilogram per hektar ([BPS] Badan Pusat Statistik Provinsi Lampung, 2015). Tanaman lada membutuhkan waktu tiga sampai empat tahun untuk memasuki usia produktif agar lada bisa dipanen (Delita, Prasmatiwi, \& Yanfika, 2015). Dalam upaya untuk mengembalikan kejayaan lada di Kabupaten Lampung Timur, sejak beberapa tahun terakhir pemerintah setempat menggalakkan kembali tanaman lada dengan memasukkan lada sebagai komoditas unggulan di Kabupaten Lampung Timur dengan mencanangkan Program Cagar Budidaya Lada di Kecamatan Margatiga. Melalui program dan perbaikan teknologi budidaya dapat meningkatkan kesejahteraan masyakatnya dengan memberdayakan potensi sektor pertanian yang ada khususnya tanaman lada sehingga meningkatkan pendapatan masyarakat. Berdasarkan uraian tersebut, maka tujuan penelitian adalah menganalisis kelayakan finansial pada tanaman lada di Kabupaten Lampung Timur. 


\section{METODELOGI PENELITIAN}

Lokasi Penelitian. Lokasi penelitian dilaksanakan di Desa Sukadana Baru Kecamatan Margatiga di Kabupaten Lampung Timur. Adapun alasan penentuan lokasi tersebut berdasarkan pertimbangan sebagai berikut : (1) Kecamatan Margatiga sebagai salah satu sentral penghasil lada yang telah dilakukan secara turun temurun, (2) Kecamatan Margatiga telah menjadi lokasi cagar budidaya lada hitam di Kabupaten Lampung Timur.

Populasi dan Teknik Pengambilan Sampel. Populasi dalam penelitian ini sebanyak 424 petani lada (Dinas Perkebunan dan Kehutanan, 2015). Teknik Pengambilan sampel tersebut didapatkan berdasarkan perhitungan (Sugiarto , 2003) dengan metode acak sederhana (simple random sampling). Adapun rumusnya sebagai berikut:

$$
n=\frac{N^{2} S^{2}}{N d^{2}+Z^{2} S^{2}}
$$

Keterangan :

$\begin{array}{lll}\mathrm{N} & = & \text { Jumlah sampel } \\ \mathrm{N} & = & \text { Jumlah populasi } \\ \mathrm{S}^{2} & = & \text { Variasi sampel }(5 \%=0,05) \\ \mathrm{Z} & = & \text { Tingkat kepercayaan }(95 \%=1,96) \\ \mathrm{d} & = & \text { derajat penyimpangan }(5 \%=0,05)\end{array}$

Berdasarkan perhitungan, jumlah sample pada lokasi penelitian di Kecamatan Margatiga Kabupaten Lampung Timur berjumlah 56 petani lada.

Metode dan Jenis Data. Dalam penelitian ini ada dua penggunaan metode yaitu metode deskriptif dan metode inferensia. Metode deskriptif berhubungan dengan pencariaan dan penyajian data agar mudah diinterpretasikan. Sedangkan metode inferensia yaitu suatu pernyataan atau kesimpulan mengenai suatu populasi yang didasarkan pada informasi dari sample yang diambil (Kaizan, Arifin, \& Santoso, 2014). Jenis data dalam penelitian ini menggunakan beberapa data, yaitu : Data Primer adalah data yang di dapatkan dari hasil wawancara atau observasi secara langsung pada petani tanaman lada Kecamatan Margatiga Kabupaten Lampung Timur. Data Sekunder adalah data yang diperoleh dari dokumen yang dimiliki oleh lembaga terkait/instansi terkait, laporan-laporan, publikasi dan pustaka lainnya yang berhubungan dengan penelitian ini

Teknik Pengumpulan Data. Dalam usaha pengumpulan data yang lengkap guna menyusun penelitian ini digunakan instrumen - instrumen penelitian antara lain interview (Wawancara), observasi (Pengamatan Langsung), dokumentasi, dan kuisoner.

Analisis Data. Analisis finansial yang digunakan dengan menghitung Net Present Value (NPV), Internal Rate of Return (IRR), Benefit-Cost Ratio (Net B/C), Gross Benefit-Cost Ratio (Gross B/C), Payback Period (PP). Rumus yang dipergunakan adalah sebagai berikut : (Ali, 2016; Ayu, Qurniati, \& Hilmanto, 2015; Gittinger. J, 1993; Gray, Simanjuntak, Sabur, Maspaitella, \& Varley, 2007; Kadariah, L. Karlina, 1978; Kaizan et al., 2014; Rio Khusnul Rizal, Ali Ibrahim Hasyim, 2017); Gray dkk., 2005; Kaizan, 2014; Ayu dkk., 2015; Ali, 2016; Rizal dkk., 2017).

Net Present Value (NPV). NPV merupakan hasil keuntungan bersih (Net Benefit) maksimal yang dapat dicapai dengan sebuah investasi modal usaha. Persamaan untuk Net Present Value(NPV) adalah sebagai berikut : 
Jurnal Penelitian Pertanian Terapan

$$
\mathrm{NPV}=\sum_{\mathrm{t}=0}^{n} \frac{\mathrm{B}_{\mathrm{t}}-\mathrm{C}_{\mathrm{t}}}{(1+\mathbf{i})^{\mathrm{t}}}
$$

Keterangan:

$\mathrm{NVP}=$ Net Present Value (Rp.)

$\mathrm{B}_{\mathrm{t}}=$ Benefit kotor proyek pada tahun ke-t

$\mathrm{C}_{\mathrm{t}}=$ Biaya kotor proyek pada tahun ke-t

$\mathrm{i}=$ Tingkat suku bunga (\%)

$\mathrm{n}=$ Umur ekonomis

$\mathrm{t}=$ Tahun ke $1,2,3 \mathrm{dst}$

Dengan kriteria penilaiannya adalah :

NPV > 0 berarti mengalami keuntungan dan dapat dilaksanakan.

NPV $=0$ berarti impas (tidak untung / tidak rugi)

NPV $<0$ berarti mengalami kerugian dan tidak dapat dilaksanakan.

Internal Rate of Return (IRR). IRR merupakan gambaran besarnya suku bunga yang terbaik sebagai syarat terjadi pengembalian modal yang diinvestasikan. Sehingga mengetahui tingkat suku bunga yang tidak menguntungkan lagi untuk berinvestasi. Persamaan untuk Internal Rate of Return (IRR) adalah sebagai berikut :

$$
\mathrm{IRR}=\mathrm{i}_{1}+\frac{\mathrm{NPV}_{1}}{\mathrm{NPV}_{1}-\mathrm{NPV}_{2}} \quad \mathrm{x}\left(\mathrm{i}_{2}-\mathrm{i}_{1}\right)
$$

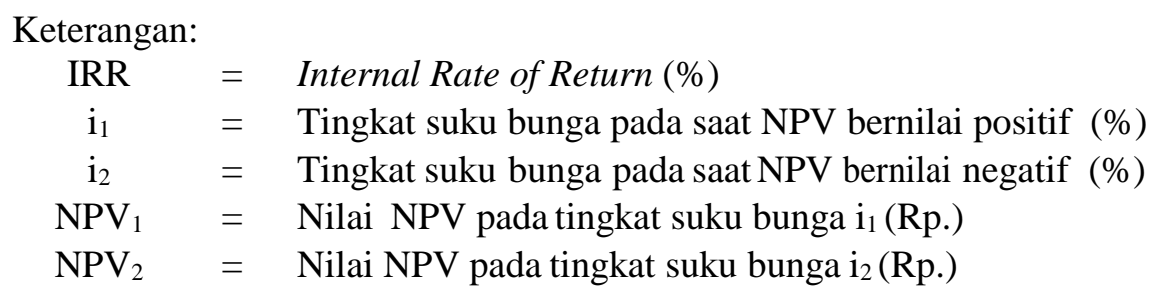

Dengan kriteria penilaiannya adalah

a. $I R R>$ Batas IRR yang ditetapkan Bank, usaha layak

b. $I R R=$ Batas IRR yang ditetapkan Bank, usaha layak

c. $I R R<$ Batas IRR yang ditetapkan Bank, usaha tidak layak

Net Benefit-Cost Ratio (Net B/C).Net B/C merupakan perbandingan antara NPV total dari keuntungan (benefit) bersih terhadap total dari biaya bersih. Net B/C merupakan angka perbandingan antara jumlah Present Value yang positif (sebagai pembilang) dengan Present Value negatif (sebagai penyebut). Persamaan untuk Net Benefit-Cost Ratio (Net B/C) adalah sebagai berikut :

$$
\text { Net } B / C=\frac{\sum_{t=0}^{n} \frac{B_{t}-C_{t}}{(1+i)^{t}}}{\sum_{t=0}^{n} \frac{C_{t}-B_{t}}{(1+i)^{t}}}
$$

Keterangan :

Net $\mathrm{B} / \mathrm{C}=$ Net Benefit-Cost Ratio 


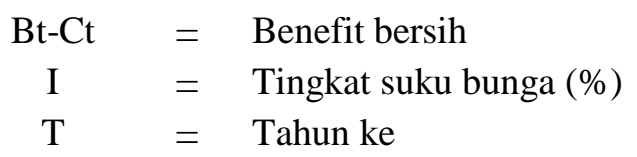

Dengan kriteria penilaiannya adalah

Net $\mathrm{B} / \mathrm{C}>1$ berarti usaha yang dilakukan layak untuk dikerjakan

Net $\mathrm{B} / \mathrm{C}=1$ berarti usaha yang dilakukan impas (tidak untung / tidak rugi)

Net $\mathrm{B} / \mathrm{C}<1$ berarti usaha yang dilakukan tidak layak untuk dikerjakan

Gross Benefit-Cost Ratio (Gross B/C). Gross B/C merupakan manfaat yang diterima usahatani dari setiap satu satuan biaya yang dikeluarkan. Gross $\mathrm{B} / \mathrm{C}$ merupakan perbandingan antara Present Value B enefit dengan Present Value Cost. Persamaan untuk Gross Benefit-Cost Ratio (Gross B/C) adalah sebagai berikut :

$$
\begin{aligned}
& \text { n } \quad B_{t} \\
& \sum_{t=0} \overline{(1+i)^{t}} \\
& \text { Gross B/C }=\frac{}{n \quad C_{t}} \\
& \sum_{t=0}(1+i)^{t}
\end{aligned}
$$

Dengan kriteria penilaiannya adalah:

a. Gross $\mathrm{B} / \mathrm{C}>1$ berarti usaha tersebut layak untuk dilaksanakan dan menguntungkan.

b. Gross $\mathrm{B} / \mathrm{C}=1$ berarti usaha tersebut mengalami impas (Break Event Point)

c. Gross $\mathrm{B} / \mathrm{C}<1$ berarti usaha tersebut tidak layak dilaksanakan dan tidak menguntungkan.

Payback Period (PP). Payback Period (PP) bertujuan ntuk mengetahui jangka waktu pengembalian modal yang ditanam dalam usaha tersebut. Persamaan untuk Payback Period (PP) adalah sebagai berikut :

$$
\mathrm{PP}=\frac{\mathrm{Ko}}{\mathrm{Ab}} \times 1 \text { tahun }
$$

Keterangan

$\mathrm{PP} \quad=$ Tahun pengembalian investasi

Ko $\quad=$ Investasi awal (Rp.)

$\mathrm{Ab} \quad=\quad$ Manfaat bersih yang diperoleh dari setiap periode (Rp.)

Dengan kriteria penilaiannya adalah:

Payback Period < Batas Payback Period yang ditetapkan Bank, Usaha Layak

Payback Period = Batas Payback Period yang ditetapkan Bank, Usaha Layak

Payback Period > Batas Payback Period yang ditetapkan Bank, Usaha Tidak Layak 


\section{HASIL DAN PEMBAHASAN \\ Keragaan Usahatani Lada}

Penggunaan bibit usahatani lada. Penggunaan bibit perlu dilakukan pemilihan, hal ini dikarenakan bibit yang baik dapat memberikan hasil produksi yang baik. Rata-rata kebutuhan bibit lada per hektar tergantung dari jarak tanam yang ditentukan petani, maka jumlah penggunaan dan biaya bibit rata-rata per 1 hektar usahatani lada per hektar sebanyak 1.360 batang. Hal ini memperlihatkan bahwa kerapatan tanaman lada yang berbeda pada petani yang memiliki lahan luas maupun lahan sempit. Sehingga petani yang memiliki lahan luas berorientasi dalam memproduksi yang tinggi dari pada lahan sempit. Harga bibit lada ditentukan oleh kualitas bibit. Harga bibit rata-rata yang digunakan petani untuk lada Rp. 2.329/batang. Sehingga biaya bibit yang harus dikeluarkan petani yaitu untuk tanaman lada sebesar Rp. 3.173.569,79.

Penggunaan Pupuk. Sarana input produksi yang penting untuk pertumbuhan dan perkembangan tanaman adalah pupuk. Jenis pupuk yang digunakan petani terdiri dari pupuk kimia dan pupuk kandang. Pupuk kimia yang digunakan antara lain Urea dan NPK. Pupuk yang digunakan petani selain pupuk kimia adalah pupuk kandang. Pada tanaman lada, sebagian petani menggunakan pupuk petroganik yang merupakan campuran pupuk kimia dan organik. Kemudian sebagian petani memperoleh pupuk kandang dari ternak yang dimilikinya. Jumlah penggunaan dan biaya pupuk kimia, kandang dan petroganik rata-rata per hektar usahatani tanaman lada dapat dilihat pada Gambar 2.

\section{Penggunaan Pupuk Pada Tanaman Lada}

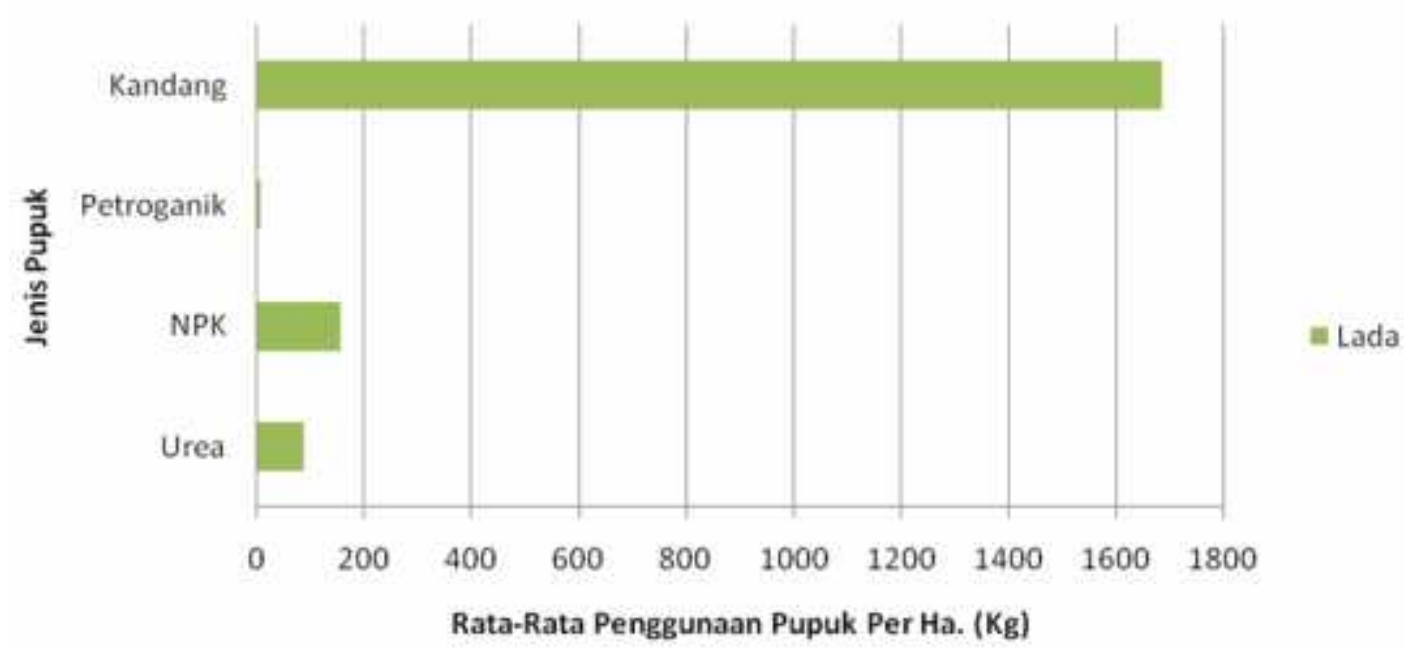

Gambar 2. Rata-rata penggunaan pupuk pada tanaman lada per hektar

Berdasarkan gambar 2, menunjukkan bahwa kebutuhan jenis pupuk yang diperlukan untuk tanaman lada berbeda. Perbedaan tersebut dikarenakan kebutuhan dari tanaman lada terhadap nutrisi dan kemampuan modal petani yang terbatas. Tanaman lada tidak memerlukan pupuk TSP dan pupuk KCL, tetapi pupuk yang dipergunakan oleh petani lada di Kecamatan Margatiga berupa pupuk urea, NPK, petroganik dan kandang. Pupuk NPK dan pupuk petroganik merupakan pupuk yang mengandung N, P dan K sehingga sebagian petani lada lebih praktis mengunakan walaupun tetap mengunakan pupuk urea. Biaya yang dikeluarkan petani lada untuk membeli pupuk sebesar Rp. 1.169.272,69. Menurut Sumantri dkk, 2004 menyatakan bahwa penggunaan dosis pupuk tergantung dari kondisi tanah, semakin subur kondisi tanah maka penggunaan pupuk semakin sedikit. 
Penggunaan Pestisida. Penggunaan pestisida dilakukan untuk mencegah serangan hama dan penyakit tanaman. Dalam usahatani, herbisida digunakan untuk memberantas gulma, fungisida digunakan untuk membrantas jamur, dan insektisida digunakan untuk membrantas hama. Bahkan penggunaan pestisida mampu menyelamatkan paling tidak sepertiga dari kehilangan hasil akibat penyakit. Sumantri et al., (2004), menyatakan bahwa penggunaan pestisida tanaman lada sangat tergantung dari jenis hama dan penyakit yang menyerang. Jenis pestisida yang digunakan pada tanaman lada yaitu sidalaris, gramoxone, ranger, lindomin, obin, noxone, fastax, furadan dan sidametrin. Penggunaan pestisida menjadi tambahan biaya yang harus dikeluarkan oleh petani selama proses produksi. Jumlah biaya pestisida yang dikeluarkan petani selama proses usahatani lada adalah Rp. 284.122,37 per ha.

Penggunaan Tenaga Kerja. Penggunaan tenaga kerja merupakan faktor produksi yang sangat penting dalam mengelola usahatani. Pada kegiatan usahatani, tenaga-tenaga tersebut terdiri dari tenaga kerja pria dan wanita yang disama-ratakan dalam satuan Hari Orang Kerja (HOK) dengan standar jam kerja sebanyak 8 jam kerja per hari berdasarkan tingkat upah yang berlaku. Dalam perhitungan usahatani, tenaga kerja terbagi menjadi tenaga kerja dalam keluarga dan tenaga kerja luar keluarga. Pemakaian tenaga kerja pada tanaman lada digunakan untuk kegiatan pengolahan lahan, penanaman pohon tiang panjat, pengajiaran, penanaman bibit lada, pemupukan, penyulaman, penyemprotan, pemangkasan, pemanenan, dan pasca panen. Rata-rata penggunaan tenaga kerja pada tanaman lada per hektar oleh petani responden dapat dilihat pada Gambar 3.

\section{Penggunaan Tenaga Kerja Pada Tanaman Lada}

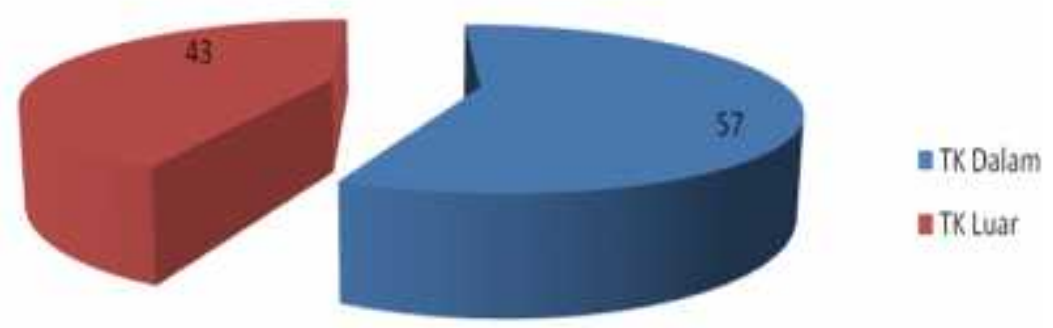

Gambar 3. Rata-rata penggunaan tenaga kerja pada tanaman lada per hektar

Berdasarkan Gambar 3. menunjukkan bahwa jumlah tenaga kerja yang digunakan pada tanaman lada tersebut berasal dari tenaga kerja dalam dan tenaga kerja luar. Dalam hal ini, petani lada lebih mengutamakan tenaga kerja dalam keluarga yang bertujuan untuk menekan biaya produksi sehingga petani akan memaksimalkan pendapatan usahataninya. Biaya tenaga kerja dalam keluarga yang dikeluarkan untuk usahatani lada rata-rata per hektar adalah Rp. 2.679.374,39 sedangkan untuk tenaga kerja luar keluarga ratarata per hektar sebesar Rp. 2.042.640,57. Besarnya biaya tenaga kerja pada tanaman lada bersumber dari kegiatan panen lada dan pemeliharaan (penyemprotan hama dan penyakit) yang dilakukan sesering mungkin.

Penggunaan Peralatan. Penggunaan peralatan dalam usahatani lada seperti cangkul, gunting pangkas, pisau, sabit/arit, koret, tembilang, handsprayer, golok dan terpal jemur. Peralatan tersebut mudah didapatkan di toko sarana prasarana pertanian di daerah penelitian. Rata-rata penyusutan untuk peralatan tersebut adalah Rp. 632.993,55 per tahun untuk tanaman lada.

\section{Analisis Kelayakan Finansial Usahatani}

Analisis kelayakan usahatani yang dilakukan dalam penelitian ini adalah analisis finansial usahatani lada. Kreteria kelayakan yang digunakan dalam usahatani lada dan kakao adalah nilai saat ini (NPV), rasio 
manfaat dan biaya (Gross B/C ratio dan Net B/C ratio), Internal Rate Return (IRR) dan Payback Period (PP). Perhitungan analisis finansial usahatani lada di Kabupaten Lampung Timur dapat dilihat pada Tabel 2.

Tabel 2. Analisis kelayakan usahatani lada pada tingkat suku bunga $17,50 \%(\mathrm{df}=0.175)$

\begin{tabular}{lc}
\hline Uraian & Usahatani Lada \\
\hline Net Presnt Value (NPV) & Rp. $32.683 .906,82$ \\
IRR $(\%)$ & $23,71 \%$ \\
Net B/C & 1,50 \\
Gross B/C & 1,35 \\
Payback Period & 7,78 \\
\hline
\end{tabular}

Sumber : Data primer diolah, 2018

Analisis finansial bertujuan untuk mengetahui kelayakan usahatani lada di Kecamatan Margatiga Kabupaten Lampung Timur. Perhitungan analisis finansial menggunkan tingkat suku bunga kredit usaha rakyat mikro Bank BRI sebesar 17,5\%. Dengan menggunakan suku bunga tersebut, maka akan didapat nilai discounting factor.

Net Present Value (NPV). Kelayakan suatu usaha dapat dinilai jika NPV >0, hal ini berarti bahwa penerimaan bersih (benefit) suatu usaha lebih besar dari total biaya (cost) yang dikeluarkan. Besarnya nilai NPV pada tanaman lada berdasarkan biaya pada tingkat suku bunga 17,5 \% sebesar Rp. 32.683.906,82. Nilai NPV tersebut menggambarkan seluruh keuntungan yang didapat dari perhitungan berdasarkan nilai uang pada saat umur ekonomisnya berakhir (time value of money). Pada usahatani tersebut nilai NPV lebih besar dari nol. Hal ini menunjukkan bahwa penerimaan bersih usahatani lada lebih besar dari total biaya yang dikeluarkan dan dengan kata lain bahwa usahatani lada di Kecamatan Margatiga Kabupaten Lampung Timur mengguntungkan dan layak untuk dikembangkan. Hal ini sesuai dengan penelitian yang pernah dilakukan Delita et al., (2015); Sumantri et al., (2004), usahatani lada secara finansial mengguntungkan.

Internal Rate of Return (IRR). Analisis IRR pada suatu usaha dapat dikatakan layak untuk dikembangkan atau menguntungkan apabila nilai IRR lebih besar dari tingkat suku bunga yang berlaku. IRR merupakan salah satu aspek keuangan yang menilai kelayakan suatu usaha untuk dikembangkan dengan melihat besarnya suku bunga. Pada saat penelitian tingkat suku bunga yang berlaku adalah sebesar 17,5\%. Dari tabel hasil analisis finansial berdasarkan biaya total didapatkan nilai IRR untuk tanaman lada adalah sebesar 23,71\% sehingga dapat dikatakan bahwa tanaman lada memiliki nilai IRR lebih besar dari tingkat suku bunga yang artinya usahatani tersebut layak untuk dikembangkan.

Net B/C Ratio. Analisis Net B/C merupakan membandingkan antara penerimaan bersih dengan biaya bersih yang telah diperhitungkan nilainya saat ini (present value). Kriteria kelayakannya adalah jika Net B/C $>1$, maka usaha tersebut mengalami keuntungan dan dapat dikembangkan. Dari hasil analisis, dengan biaya total didapatkan nilai Net B/C sebesar 1,50 (untuk tanaman lada), dari tanaman lada Net B/C tersebut diatas 1 maka dapat dikatakan bahwa usahatani lada di Kecamatan Margatiga Kabupaten Lampung Timur menguntungkan dan layak untuk dikembangkan. Nilai Net B/C untuk tanaman lada memiliki arti, dimana tanaman lada dengan nilai Net B/C sebesar 1,50 berarti bahwa setiap Rp. 1.000,00 biaya bersih yang dikeluarkan akan menghasilkan penerimaan bersih sebesar Rp. 1.500,00.

Gross B/C Ratio. Analisis Gross B/C yang diperoleh dari hasil analisis finansial dengan biaya total pada suku bunga 17,5\% sebesar 1,35 untuk tanaman lada, hal ini berarti usahatani lada layak untuk diusahakan dan dikembangkan karena setiap Rp. 1.000,00 biaya yang dikeluarkan akan menghasilkan penerimaan usahatani lada sebesar Rp. 1.350,00.

Payback Period (Pp). Payback Period merupakan analisis untuk mengetahui jangka waktu pengembalian investasi oleh keuntungan bersih suatu usaha. Bila waktu pengembalian investasi lebih pendek 
dari pada umur ekonomis usaha, maka usaha tersebut layak untuk dikembangkan. Pada hasil analisis finansial berdasarkan biaya total, didapatkan payback period bernilai 7,78 tahun untuk tanaman lada, yang artinya biaya investasi usahatani lada dapat dikembalikan dalam jangka waktu lebih pendek dari umur proyek yaitu 30 tahun.

\section{KESIMPULAN}

Kesimpulan dalam penelitian kelayakan finansial usahatani lada dengan melihat rasio manfaat dan biaya (Gross B/C ratio dan Net B/C ratio), Net Present Value (NPV), Internal Rate Return (IRR) dan Payback Period (PP) maka usahatani lada masih menguntungkan dan layak untuk dikembangkan. Hal ini dapat dilihat dari pendapatan yang diterima petani lada masih lebih tinggi.

Saran yang diberikan atas dasar hasil penelitian khususnya tanaman lada, dimana tanaman lada masih memiliki peluang peningkatan produksi dengan melakukan perbaikan teknik produksi (intensifikasi) melalui inovasi teknologi budidaya.

\section{UCAPAN TERIMA KASIH}

Terima kasih disampaikan kepada Kemenristekdikti (Kementerian Riset, Teknologi, dan Pendidikan Tinggi) yang telah mendanai penelitian ini melalui Hibah Penelitian.

\section{DAFTAR PUSTAKA}

[BPS] Badan Pusat Statistik Provinsi Lampung. (2015). Lampung Dalam Angka. Bandar Lampung.

Ali, H. (2016). Analisis Kelayakan Usahatani Pemanfaatan Ruang Tanaman Kakao ( Theobrama Cacao L .) Berdasarkan Kelas Kesesuaian Lahan Ekonomi Di Kabupaten Sidenreng Rappang Feasibility Farming Analysis of Space Utilization of Cocoa (Theobrama cacao L.) Based on Econom. 5(April), 41-51.

Ayu, H. Y., Qurniati, R., \& Hilmanto, R. (2015). Analisis Finansial dan Komposisi Tanaman dalam Rangka Persiapan Pengajuan Izin HKM (Studi Kasus Desa Margosari Kecamatan Pagelaran Utara Kabupaten Pringsewu). Jurnal Sylva Lestari, 3(1), 31-40. https://doi.org/10.23960/js11331-40

Delita, A. L., Prasmatiwi, F. E., \& Yanfika, H. (2015). Analisis Kelayakan Finansial dan Efisiensi Pemasaran Lada di Kecamatan Gunung Labuhan Kabupaten Way Kanan. Jiia, 3(2), 130-139.

Dinas Perkebunan dan Kehutanan. (2015). Jumlah Petani di Desa Margatiga. Lampung Timur.

Fatimah. (2013). Analisis Keunggulan Kompetitif dan Komperatif Komoditas Lada Hitam (Pipper Nigrum L.) di Kabupaten Lampung Utara (Tesis). Jurusan Magister Agribisnis. Universitas Lampung. Lampung.

Gittinger. J, P. (1993). Analisis Proyek-Proyek Pertanian. Jakarta: Universitas Indonesia Press.

Gray, C., Simanjuntak, P., Sabur, L. K., Maspaitella, P. F. L., \& Varley, R. C. G. (2007). Pengantar Evaluasi Proyek. In PT Gramedia Pustaka Utama. Retrieved from https://books.google.co.id/books /about/Pengantar_Evaluasi_Proyek_Ed2.html?hl=id\&id=KlsYdLc7EEkC\&redir_esc=y

Kadariah, L. Karlina, C. G. (1978). Pengantar Evaluasi Proyek. Jakarta: Fakultas Ekonomi Universitas Indonesia.

Kaizan, Arifin, B., \& Santoso, H. (2014). Kelayakan Finansial Dan Nilai Ekonomi Lahan (Land Rent) Pada Penggantian Usahatani Kopi Menjadi Karet Di Kabupaten Way Kanan Provinsi Lampung | Kaizan | Jurnal Ilmu-Ilmu Agribisnis. JIIA, 2. Retrieved from http://jurnal.fp.unila.ac.id /index.php/JIA /article/view/984/890 
Kementerian Pertanian. (2015). Outlook Lada Komoditas Subsektor Perkebunan. Jakarta: Pusat Data dan Sistem Informasi Pertanian.

Kementerian Pertanian. (2018). Outlook Lada Komoditas Subsektor Perkebunan. Jakarta: Pusat Data dan Sistem Informasi Pertanian.

Mangiring, Z. dan W. (2017). Analisis Biaya Transaksi pada Kelembagaan Pertanian Gapoktan Penerima Program Pengembangan Usaha Agribisnis Pedesaan (PUAP) di Desa Raman Aji Kecamatan Raman Utara Kabupaten Lampung Timur. Jurnal Pertanian Terapan, 17(3), 186-196.

Rio Khusnul Rizal, Ali Ibrahim Hasyim, S. S. (2017). Kelayakan Ekonomi Dan Pemasaran Kakao Di Kabupaten Lampung Selatan. Jiia, Volume 5 No. 4, November 2017, 5(4), 352-359.

Sugiarto, D. Siagian, L.S. Sunarto, dan D. S. O. (2003). Teknik Sampling. Jakarta: Gramedia Pustaka Utama.

Sumantri, B., Priyono, B. S., \& Isronita, M. (2004). Analisis kelayakan finansial usahatani lada (Piper nigrum L.) di Desa Kunduran Kecamatan Ulu Musi Kabupaten Lahat Sumatera Selatan. Jurnal Ilmu Ilmu Pertanian Indonesia, 6(1), 32-42.

Suwanto. (2017). Analisis daya saing dan pemasaran lada hitam di kabupaten lampung timur.

Syamsuddin, \& Hatta Muhammad. (2014). Di Sulawesi Barat Analysis of Potential and Development Opportunity of Cocoa in West Sulawesi. 16(1), 92-101. 